\title{
Diagnóstico de práticas da gestão do conhecimento na estruturação de processos organizacionais em instituição privada de ensino superior a distância
}

\author{
AthurGalbetoBacelarcaCuzUpia Doutor em Economia. Centro Universitário de Maringá (UNICESUMAR) - Brasil. \\ arthurbacellar@yahoo.com.br. \\ JulianaceCósiaBanto Mestre em Gestão do Conhecimento nas Organizações. Centro Universitário de Maringá \\ (UNICESUMAR) Brasil - jcbent0805@hotmail.com \\ FávioBartdozá Doutor em Engenharia de Computacãa. Centro Universitário de Maringá (UNICESUMAR) - Brasil. \\ flavio.bortolozzi.53@gmail.com \\ ByMtieMmada Doutora em História Econômica. Centro Universitário de Maringá (UNICESUMAR) - Brasil. \\ elymitie.m@gmail.com
}

\begin{abstract}
RESUMO
Os cursos superiores vêm crescendo de forma exponencial, principalmente na modalidade a distância, e a competição entre as Instituições de Ensino Superior (IES) privadas se acirram. Este fato obrigou as IES a reverem seus métodos de gestão quanto à estruturação de processos organizacionais a fim de se adequarem ao novo modelo educacional, com vistas a aumentar suas vantagens competitivas. Dada a sua importância para as organizações, as práticas de Gestão do Conhecimento $(\mathrm{GC})$ relacionadas à estruturação de processos organizacionais devem fazer parte dos planejamentos estratégicos e do Plano de Desenvolvimento Institucional (PDI) de uma IES, pois se vivencia atualmente a era das organizações do conhecimento e gerenciar de forma eficiente o conhecimento de seus colaboradores, poderá obter vantagem competitiva. Diante disso, o objetivo geral desta pesquisa consistiu em analisar as práticas de GC relacionadas à estruturação de processos organizacionais em uma IES privada que atua na modalidade de ensino a distância no norte do Paraná. A pesquisa caracteriza-se como um estudo de caso envolvendo toda a população de 17 coordenadores, responsáveis pela gestão de cursos de graduação na modalidade de educação a distância. Como técnica de coleta de dados, um questionário desenvolvido pelo Instituto de Pesquisa Econômica Aplicada (IPEA) foi utilizado, visando identificar o estágio de implantação das práticas de GC. Como principal conclusão, observou-se que a IES pesquisada possui um nível efetivo de implantação das suas práticas de GC de processos organizacionais baixo, algo que está em desacordo com o ambiente altamente competitivo em que elas estão inseridas.
\end{abstract}

Palavras-Chave: Instituição de ensino superior. Diagnóstico. Gestão do conhecimento. Processos organizacionais. Gestão de capital intelectual.

\section{Diagnosis of knowledge management practices in the structuring of organizational processes in a private institution of higher education in distance- learning modality}

\begin{abstract}
Higher education courses have been growing exponentially, especially in the distance-learning modality and competition between private higher education institutions has intensified. This fact forced the Higher Education Institutions (HEI) to review their management methods regarding the structuring of organizational processes in order to adapt to the new educational model, and to increase their competitive advantages. Due to their importance to the institutions, the practices of Knowledge Management (KM) related to the structuring of organizational processes should be part of the strategic planning and the Institutional Development Plan (IDP) of an HEl, given that we live in the era of knowledge organization and those who manage knowledge in an efficient manner may obtain a competitive advantage. Therefore, the general objective of this research is to analyze the KM practices related to the structuring of organizational processes in a private HEl that operates in the distance- learning modality in the north of Paraná. The research is characterized as a case study involving the entire population of 17 coordinators, responsible for the management of undergraduate courses in the modality of distance-learning. As data collection technique, a questionnaire developed by the Institute of Applied Economic Research (IPEA) was used to identify the stage of implementation of GC practices. As a main conclusion, it was observed, through the analysis of the data collected, that the researched HEl has a low level of implementation of its KM practices of organizational processes, something that is at odds with the highly competitive environment in which they are inserted.
\end{abstract}

Keywords: Higher education institution. Diagnosis. Knowledge management. Organizational processes. Management of intellectual capital. 


\section{INTRODUÇÃO}

A Gestão do Conhecimento (GC), segundo Gonzalez e Martins (2017), é uma temática que tem suscitado cada vez mais atenção das organizações. Diversos autores nas últimas décadas têm se dedicado a discutir a importância da GC para as organizações, salientando a importância que o tema adquiriu como estratégia de sobrevivência e competitividade (NONAKA; TAKEUCHI, 1997; STEWART, 1998; SVEIBY; MARTINS, 2005; TERRA, 2001).

Segundo Sveiby e Martins (2005, p. 3), "a Gestão do Conhecimento não é mais uma moda de eficiência operacional. Faz parte da estratégia empresarial" e vem se consolidando como fator crítico de sucesso para a criação de vantagens competitivas nas organizações.

No Brasil, a expansão nos últimos anos do sistema universitário vem trazendo uma série de novas exigências para as IES. Dentre elas, Bolson (2012) cita a necessidade de os dirigentes universitários atuarem em vários setores das instituições, com competência para superarem os desafios impostos por um ambiente caracterizado por sua complexidade e com objetivos voltados para a criação e a difusão do conhecimento (SILVA, 2000). Ainda segundo o mesmo autor, a GC no contexto de uma IES pode ser compreendida como 0 processo de criação de um ambiente de ensino-aprendizagem, a partir da criatividade, do julgamento e do diálogo entre os indivíduos. De acordo com Sveiby e Martins (2005), na sociedade do conhecimento, os indivíduos necessitam desenvolver a proatividade, a flexibilidade, a multidisciplinaridade e a abertura para novos ensinamentos, algo que é facilitado pelo uso da GC.

Os cursos superiores vêm crescendo de forma exponencial e competição entre as IES privadas se acirram. Este fato obriga as IES a reverem seus métodos de gestão quanto à estruturação de processos organizacionais a fim de adequarem-se ao novo modelo educacional, com vistas a aumentar suas vantagens competitivas. A busca pela competência nesse processo leva as organizações a tratarem o conhecimento com uma visão muito mais ampla de gestão. Conforme Bolson (2012) o diferencial de uma organização não está na quantidade de conhecimento que ela produz, mas sim na eficácia em que o processo de GC ocorre na IES.

Ponchirolli (2009) entende que somente através do conhecimento as organizações podem inovar, mantendo-se vivas, ativas e competitivas. Segundo o mesmo autor, o componente intelectual assumiu a supremacia, em detrimento do antigo modelo físico. Portanto, é urgente e indispensável modificar formas hierárquicas ultrapassadas e cerceadoras da criatividade.

Dada a sua importância nos tempos atuais para as organizações, as práticas de GC relacionadas à estruturação de processos organizacionais devem fazer parte dos planejamentos estratégicos e do Plano de Desenvolvimento Institucional (PDI) de uma IES, pois perante a era do conhecimento que ora se vivencia, leva a uma situação em que aquele que souber gerenciar de forma eficiente o conhecimento de seus colaboradores terá uma grande vantagem competitiva.

Diante disso, o objetivo geral deste trabalho foi de analisar as práticas de gestão do conhecimento relacionadas à estruturação de processos organizacionais em uma IES privada que atua na modalidade de ensino à distância no norte do Paraná.

Para tal, além desta breve introdução, este artigo contém mais quatro seções. A segunda seção discutirá sobre a GC nas organizações, apresentando seus conceitos, práticas e sua importância para as IES. A terceira seção trará os aspectos metodo lógicos. A quarta seção apresentará os resultados e discussões. Por fim, a quinta seção exibirá os comentários finais.

\section{A GESTÃO DO CONHECIMENTO NAS ORGANIZAÇÕES: CONCEITOS, PRÁTICAS E SUA IMPORTÂNCIA PARA AS IES}

Em uma sociedade moderna, o conhecimento apresenta-se como fonte de recurso econômico proeminente e importante no processo inovador e competitivo das organizações, sendo a riqueza o produto do conhecimento e da informação. 
Cassiolato (1999, p. 172-173) já identificava as mudanças nas ocupações do mercado de trabalho provenientes do que denominou a 'Era da Informação':

De fato, a proporção de trabalho que simplesmente manuseia bens tangíveis, ao longo do processo produtivo, tem cada vez mais se tornado menos significativa do que a proporção do trabalho responsável pela produção, distribuição e processamento do conhecimento. A expansão - absoluta e relativa - das atividades e dos setores 'intensivos em conhecimento' tem caracterizado os processos de desenvolvimento nas últimas décadas.

A ampliação da capacidade de captura, armazenamento e disseminação de dados e informação imputaram grandes transformações nas organizações nas últimas décadas do século $X X$, vivenciando-se o que se denominou a 'Era da Informação' (CASSIOLATO, 1999). Conforme Davenport e Prusak (1998, p. 2) é "um conjunto de fatos distintos e objetivos, relativos a eventos". Quando associados a um contexto dando um significado para quem o utiliza, torna-se informação. 0 conhecimento, por sua vez, deriva da informação.

Em período recente, efetiva-se a transição para a Era do Conhecimento, em que o conhecimento ganhou notoriedade junto às organizações no momento em que foi identificado como um dos fatores responsáveis pela sobrevivência da empresa no mercado (SCHREIBER, 2015). 0 conhecimento não é algo novo, mas a novidade está contida, segundo Davenport e Prusak (1998, p. 14), "em reconhecer o conhecimento como um ativo corporativo e entender a necessidade de geri-lo e cercá-lo do mesmo cuidado dedicado a obtenção de valor de outros ativos mais tangíveis".

Sendo assim, o gestor pode, de diversas formas, gerenciar o conhecimento existente na organização. Porém, em primeira instância, necessita identificar, conhecer e mapear esse conhecimento, para então definir estratégias de gestão. Desta forma, desde a 'Era da Informação', segundo Stewart (1998, p. 11), "[...] encontrar e estimular o capital intelectual, armazená-lo, vendê-lo e compartilhá-lo tornou-se a tarefa econômica mais importante dos indivíduos, das empresas e dos países".

Desse modo, entende-se que o conhecimento adquiriu o papel precursor de mudança de uma economia de produção para uma economia de serviços, onde ainda, segundo Bell (1974, p. 169), "quando o conhecimento se torna envolvido de alguma forma sistemática na transformação aplicada dos recursos, então se pode dizer que o conhecimento não é trabalho, é a fonte de valor".

Nesse sentido, o conhecimento contido na organização que ajuda a compor o capital intelectual das empresas, passa a ser o foco das discussões das entidades que pretendem se manter competitivas. 0 capital intelectual das empresas, que é formado pelo conhecimento tácito e explícito, tem seu valor constituído pela harmonia de ideias e valores da empresa, com a alta gerência e os objetivos estratégicos, além da potencialidade para a criação de rede de conhecimento na organização (NONAKA, 1991).

Assim, pode-se retomar Polanyi (1966), que é precursor no entendimento sobre o conhecimento tácito e explícito, para compreender como o conhecimento se dá também no âmbito organizacional. Conforme o autor, o conhecimento tácito é o princípio dominante de todo o conhecimento, já o conhecimento explícito é entendido como verdadeiro a partir do entendimento tácito. Ainda segundo Polanyi (1966), o conhecimento tácito é intuitivo, espontâneo e inclui uma porção de informações conceituais e sensoriais, ou seja, modelos mentais que auxiliam no momento de entender ou dar sentido a alguma coisa. Desta maneira, 0 autor preconiza o entendimento do conhecimento tácito a partir do fato de que não é possível codificá-lo em sua totalidade, uma vez que esse conhecimento é pessoal e que é possível saber muito mais do que se pode escrever ou representar. "O conhecimento explícito precisa ser tacitamente compreendido e aplicado. Assim sendo, todo conhecimento ou é tácito ou se apoia no conhecimento tácito. Um conhecimento totalmente explícito é impensável" (POLANYI, 1966, p. 144).

Nonaka e Takeuchi (2008) entendem o conhecimento tácito como uma importante dimensão cognitiva que consiste em crenças, valores, emoções, intuições e palpites que não são facilmente visíveis e explicáveis.

[0 conhecimento tácito] é altamente pessoal e difícil de formalizar, tornando-se de comunicação e compartilhamento dificultoso. (...) 0 conhecimento tácito está 
profundamente enraizado nas ações e na experiência corporal do indivíduo, assim como nos ideais, valores ou emoções que ele incorpora (NONAKA; TAKEUCHI, 2008, p. 19).

Pode-se inferir, portanto, que o conhecimento tácito - que é tido como uma forma de conhecimento intuitivo e inconsciente - é tanto uma forma de conhecimento pessoal, dificilmente compartilhada com os demais, como também uma forma de conhecimento social, mantido pelas comunidades de prática no ambiente de trabalho.

Diante dessa 'Era da Informação', as organizações empresariais de todos os tipos estão percebendo a importância da aprendizagem organizacional para a construção das suas vantagens competitivas. Neste sentido, estas organizações estão tendo que lidar com questões referentes à Gestão do Conhecimento, Gestão de Competências e Inovações, áreas que estão diretamente relacionadas entre si.

Segundo Zangiski, Lima e Costa $(2009$, p. 4), “(...) a aprendizagem organizacional refere-se ao processamento eficaz, interpretação e resposta de informações internas e externas à organização, e a discussão principal está relacionada à quais formas de mudança estão associadas à aprendizagem". Segundo os autores, a aprendizagem organizacional origina-se das relações sociais, e para a sua compreensão faz-se necessário identificar "(...) a forma pela qual as empresas constroem, incrementam e organizam conhecimentos e rotinas, e as suas relações com resultados e processos que ocorrem no interior das organizações" (2009, p. 4).

Segundo Argyris e Schön (1996), pode-se observar a existência de dois tipos de aprendizagem: a aprendizagem do tipo single-loop e a do tipo double-loop. A aprendizagem do tipo single-loop é a que busca manter o conhecimento através da mudança de estratégias de ação ou suposições acerca desta estratégia, de tal forma que se detecte e corrija o erro, mas sem alterar o modelo vigente. Ou seja, esta forma de aprendizagem busca detectar erros nas estratégias organizacionais e suas suposições sem alterar as normas e valores da organização. Já a aprendizagem do tipo double-loop, que é a mais indicada para mudanças na cultura organizacional, questiona e revisa os princípios que se aprende, implicando em mudanças não só das suas estratégias e suposições, como também dos valores da organização.

A GC é o processo no qual as organizações buscam realizar a gestão das suas atividades de forma a promover o desenvolvimento do conhecimento, tal que proporcione o aumento da sua competitividade. Dessa forma, observa-se que a GC visa o aumento da competitividade das organizações através do uso de estratégias que desenvolva o conhecimento organizacional. A competência organizacional é a habilidade que a organização possui de coordenar as suas estratégias, capacitações e distribuições de recursos de forma a ampliar a sua competitividade (ZANGISKI; LIMA; COSTA, 2009). Conforme Zangiski, Lima e Costa (2009, p. 7), "as competências organizacionais sustentam as potencialidades de acesso e a permanência nos mais variados mercados". Para alcançar e manter competitividade faz-se importante que as organizações tenham capacidade de gerar inovações de produtos e de processos. De acordo com Albuquerque Junior, Lazaro e Lima (2011, p. 27), "as transformações tecnológicas e as respostas corretas às necessidades dos mercados demandam, dessa forma, a construção de competências para competir por meio de inovaçóes".

As práticas de GC de estruturação de processos organizacionais - que possuem como função facilitar a geração, retenção, organização e disseminação do conhecimento organizacional - auxiliam na construção de competências organizacionais, possibilitando, assim, uma maior competitividade das organizações que as utilizam. A próxima seção trará uma análise das práticas de GC relacionadas à estruturação de processos organizacionais.

\subsection{Práticas de GC relacionadas à estruturação de processos organizacionais}

Os processos organizacionais apresentam-se como instrumentos da implementação das estratégias da empresa com o intuito de aproveitar as oportunidades inerentes ao negócio e diminuir os riscos apresentados pelas ameaças identificadas no ambiente organizacional. Assim, infere-se que a GC, por meio das práticas relacionadas aos processos organizacionais, auxilia na execução dos procedimentos, normas e 
regras, otimizando a transformação em resultados positivos para a organização (BATISTA, 2006). Os processos organizacionais possuem diversas práticas.

A prática Benchmarking (interno e externo), para Batista (2006, p. 19), está relacionada à "busca sistemática das melhores referências para comparação aos processos, produtos e serviços da organização". Para Teixeira Filho (2000) e Seibel (2004), trata-se de um modelo gerencial que procura identificar, compreender, documentar e disseminar os fatores que levaram ao sucesso empresas reconhecidas como líderes de suas atividades. A execução dessa prática passa do planejamento à definição de processos ou áreas que devem ser melhoradas, assim como definição de empresas parceiras (SEIBEL, 2004). Dessa maneira, a equipe selecionada para o processo deve estar comprometida na obtenção e análise de dados coletados, comparação de processos e, consequentemente, a implementação da mudança, exigindo um líder responsável pelo processo e supervisão. Para Purcidonio (2008, p. 60), "o Benchmarking permite identificar práticas organizacionais que proporcionem um desempenho superior, focando esforços onde resultará nos melhores resultados para a empresa".

As Melhores Práticas (best practices) buscam identificar, capturar e compartilhar as melhores práticas nas diversas atividades organizacionais. Para Batista (2006), esse tipo de prática pode ser definido como um procedimento validado para a realização de uma tarefa ou para solução de um problema, incluindo o contexto na qual pode ser aplicada. 0 material produzido pela prática pode ser documentado por meio de bancos de dados, manuais ou diretrizes na organização. A referida prática fornece informações valiosas sobre as atitudes a serem tomadas pela organização para que alcance o nível desejável de maturidade, identificando os pontos fortes e áreas passíveis de aperfeiçoamento (YOUNG, 2010). Organizações adotam modelos de caráter descritivo e normativo de níveis de maturidade para auxiliar a adoção das Melhores Práticas, e alguns modelos consideram três dimensões: processos (estratégia, liderança), sistemas (tecnologia, ambiente) e pessoas (capacidades). Um exemplo é o Capability Maturity Model Integration - CMMI, que é muito utilizado por empresas de Tecnologia da Informação para adotar Melhores Práticas (EKIONEA; BERNARD; PLAISENT, 2011).

A prática denominada Banco de Competências Organizacionais, de acordo com Batista (2006), tratase de um repositório de informações que permite localizar os conhecimentos na organização, incluindo fontes de consulta e pessoas ou equipes detentoras de determinado conhecimento. Conforme Gattoni (2000), referese ao armazenamento das conexões entre os profissionais e as habilidades e competências que os mesmos possuem.

Mapeamento ou Auditoria do Conhecimento consiste em uma prática que permite às organizações identificar e catego rizar os ativos de conhecimento dentro de sua organização - pessoas, processos, conteúdo e tecnologia (YOUNG, 2010). Por meio dessa prática é possível mapear as informações para melhor utilização dos recursos. 0 propósito principal do mapa do conhecimento consiste em fazer com que as pessoas possam saber onde se localiza o conhecimento requerido, conectando "quem quer saber a quem (ou o quê) sabe" (ANDRADE; SANTIAGO, 2001, p. 2). Batista (2006, p. 21) conceitua a prática como "o registro do conhecimento organizacional sobre processos, produtos, serviços e relacionamento com os clientes". A prática permite a elaboração de mapas ou árvores de conhecimento, descrevendo fluxos e relacionamentos de indivíduos, grupos ou a organização como um todo. Burnett, Illingworth e Webster (2004) defendem essa prática como um processo importante na determinação e ilustração do conhecimento no âmbito organizacional, pois consiste no processo de identificar o conhecimento que o gestor julga ser necessário ao sucesso do negócio e ainda identificar as duplicidades ou lacunas relacionadas aos tipos de conhecimento. A Auditoria do Conhecimento auxilia a organização na verificação, revisão e organização do conhecimento e das práticas (atividades) da GC, ou seja, qual conhecimento está sendo gerido e se há eficácia nessa gestão. Além disso, essa prática contribui para a investigação de como o colaborador percebe a eficácia da GC, pois avalia o conhecimento quanto ao ambiente, uso e compartilhamento (HYLTON, 2002).

A Memória Organizacional, de acordo com Pereira, Silva e Pinto (2016, p.364) "está diretamente relacionado à aprendizagem organizacional e a gestão do conhecimento". Segundo Conklin (2001), aumenta o conhecimento, pois captura, organiza, divulga e reutiliza o conhecimento criado pelos colaboradores dentro da organização, objetivando uma representação explícita do conhecimento e das informações a fim de facilitar o acesso, compartilhamento e reutilização por todos os colaboradores da empresa. Infere-se que o 
conhecimento dos indivíduos e suas experiências vividas na organização apresentam-se de maneira fundamental para criação de novos conhecimentos, devendo ser preservados para serem utilizados como ponto de partida para criação de novos conhecimentos. Abecker et al. (1998) salienta que uma das principais funções da Memória Organizacional é garantir maior competitividade da organização, tendo-se em vista o aperfeiçoamento da forma como ela gerencia o conhecimento organizacional. A prática é conceituada por Batista (2006, p. 21) como:

Relatos de experiências nas quais se registram o que aconteceu, o que se esperava que acontecesse, a análise das causas das diferenças e o que foi aprendido durante o processo. A gestão de conteúdo mantém atualizadas as informações, ideias, experiências, lições aprendidas e melhores práticas documentadas na base de conhecimentos.

Os registros das lições aprendidas podem ser utilizados após o término de um projeto com o objetivo de estimular a troca de ideias entre os participantes da atividade com outras áreas da organização. Essa prática permite apontar os pontos fortes e de melhoria - identificando possíveis soluções - de cada projeto, alertando sobre os riscos que podem estar presentes em projetos semelhantes no futuro (BATISTA, 2006).

Sistemas de Inteligência Organizacional também são encontrados na literatura como sistemas de inteligência empresarial ou inteligência competitiva. Esses sistemas estabelecem processos referentes à aprendizagem organizacional por meio da transformação de dados e informações em inteligência. Inclui a captura e a conversão de informações para extração do conhecimento como forma de apoiar os gestores na tomada de decisão (MACHADO;URPIA; DAL FORNO, 2017; BENTO et al., 2016; BATISTA 2012-2006). Esta prática caracteriza-se pela capacidade da organização de reunir informações, inovar e criar conhecimento atuando efetivamente com o conhecimento que gerou. Neste contexto, o desenvolvimento da Inteligência Organizacional apresenta-se de forma imprescindível para a organização que almeja atender aos desafios do ambiente ao qual está inserida. A inteligência se baseará na criação do conhecimento para promover o aprendizado organizacional, permitindo e estimulando a inovação e adaptação da organização às complexidades inerentes ao negócio/ambiente.

A prática denominada como Sistema de Gestão por Competências possui orientação no sentido de avaliar as competências internas, determinar quais competências essenciais são necessárias e definir estratégias para superar as deficiências de competências identificadas comparativamente, no nível individual e organizacional (MACHADO; URPIA; DAL FORNO, 2017; BENTO et al., 2016; APQC, 2014; ARAÚJ O; MARTINS, 2014; BATISTA et al., 2014; BATISTA, 2012; BATISTA, 2006). Segundo Dutra (2001), orienta esforços no sentido de fomentar o planejamento, a captação, o desenvolvimento e a avaliação, individual ou coletiva, nos diversos níveis da organização. Esta prática, entendida como uma estratégia de gestão, propõe determinar as competências essenciais à organização, avaliar a capacitação interna com relação aos domínios correspondentes a essas competências e definir os conhecimentos e habilidades que são necessários para superar as deficiências existentes com relação ao nível desejado para a organização, desdobrando-se em competências profissionais, permitindo seu desenvolvimento nos colaboradores (DUTRA, 2001).

Banco de Competências Individuais pode ser entendido como uma prática gerencial que possibilita o mapeamento e a gestão do conhecimento individual e institucional. Ou seja, constitui-se tal como um repositório de informações que especifica de forma abrangente as competências humanas (conhecimentos, habilidades e atitudes) no contexto organizacional, além de disponibilizar informações sobre a capacidade científica, artística e cultural dos colaboradores (MACHADO; URPIA; DAL FORNO, 2017; BENTO et al., 2016; APQC, 2014; BATISTA, 2012; BATISTA, 2006). A forma mais simples é uma lista on-line do pessoal, com um perfil da experiência e com as áreas de especialidade de cada usuário. Também encontrada na literatura como banco de talentos ou páginas amarelas, esta prática objetiva possibilitar aos colaboradores seguir as trilhas do conhecimento deixadas na organização, sendo possível chegar aos indivíduos que possuem real expertise em determinado assunto ou problema a ser solucionado. A prática se estabelece por meio de treinamento e aperfeiçoamento realizados pela organização, ou ainda por meio de mapeamento mais amplo disponível em página normal de internet, que exibe o perfil de to dos os colaboradores da organização, sendo organizado em 
ordem alfabética e classificado por cargo, setor, experiências, informações sobre o conhecimento tácito e habilidades processuais, além dos contatos.

A prática denominada de Gestão do Capital Intelectual ou Gestão dos Ativos Intangíveis é definida como a junção de ativos intangíveis composto por talentos, ideias e insights apresentados por todos os envolvidos no contexto organizacional, assim como a qualidade e harmonia entre empresa, fornecedores e clientes. Esta prática tem relação com a gestão dos ativos humanos, estrutural e de relacionamento - podendo incluir mapeamento dos ativos organizacionais intangíveis, gestão do capital humano, gestão do capital do cliente e política de prop riedade intelectual - isto com vistas a renovar, organizar, avaliar, proteger e aumentar a disponibilidade dos ativos que representam os conhecimentos presentes no âmbito organizacional (BENTO et al., 2016; APQC, 2014; FREIRE; SPANHOL, 2014; BATISTA 2012-2006). A combinação desses fatores, aliados a um sistema gerencial e em conformidade com os objetivos da organização, geram conhecimentos capazes de promover a inovação e reestruturação dos processos de forma contínua, proporcionando bons resultados (STEWART, 1998).

\section{METODOLOGIA}

Com o objetivo de construir um arcabouço teórico sobre a GC, principalmente sobre a estruturação de processos organizacionais, realizaram-se levantamentos bibliográficos, por meio de pesquisas em livros e artigos científicos.

Como a pesquisa se propõe a estudar uma IES privada que atua na modalidade de educação a distância (EaD) e se localiza no norte do Paraná, caracterizando-se como estudo de caso. Com o intuito de preservar o sigilo das informações prestadas, a instituição foi denominada de 'IES X'. Todos os dezessete coordenadores de curso de graduação dessa instituição, que são responsáveis pela gestão de cursos de graduação no EaD, participaram da presente pesquisa, o que significa que a pesquisa englobou toda população ou universo. Ou seja, foram coletados todos os dados referentes ao fenômeno de interesse da presente pesquisa.

Como técnica de coleta de dados, foi aplicado um questionário desenvolvido e validado pelo Instituto de Pesquisa Econômica Aplicada (IPEA)1, que foi amplamente utilizado em diversos estudos realizados por Batista $(2006,2012)$ e Batista et al. $(2005 ; 2007 ; 2014)$. 0 questionário se refere a uma lista com vinte e sete práticas de GC que permite a identificação do grau de alcance e do estágio de implantação das práticas de GC nas instituições. Para esta pesquisa apenas o estágio de implantação será analisado, pois este permite uma percepção do nível de integração referente aos planos, práticas e/ou ações de GC.

A aplicação do instrumento de pesquisa ocorreu no mês de novembro de 2015 a todos os gestores de forma presencial. Antes de serem submetidos ao questionário, os respondentes receberam orientações, individualmente, a respeito de cada uma das práticas, bem como receberam uma lista contendo as vinte e sete práticas e seus respectivos conceitos.

Seguindo a classificação utilizada por Batista $(2006,2012)$, as práticas e ações contidas no questionário podem ser agrupadas em três categorias:

I. Práticas relacionadas principalmente aos aspectos de gestão de recursos humanos, que facilitam a transferência, a disseminação e o compartilhamento de informações e de conhecimento.

II. Práticas ligadas primariamente à estruturação dos processos organizacionais, que funcionam como facilitadores da geração, retenção, organização e disseminação do conhecimento organizacional.

III. Práticas cujo foco central é a base tecnológica e funcional, que serve de suporte à gestão do conhecimento organizacional, incluindo a automação da gestão da informação, dos

1 O questionário utilizado na pesquisa está disponível no site do IPEA (http://www.ipea.gov.br/portal/ images/stories/PDFs/TDs/td 1316.pdf). 
aplicativos e das ferramentas de Tecnologia da Informação (TI) para captura, difusão e colaboração.

Para alcançar o objetivo geral desse trabalho, que consistiu em analisar as práticas de GC relacionadas à estruturação de processos organizacionais na IES $X$, a segunda categoria foi analisada. Para tal, através do levantamento bibliográfico realizado, verificou-se que as seguintes práticas contidas no questionário se relacionavam com a estruturação de processos organizacionais. São elas: Benchmarking; Melhores Práticas; Memória Organizacional; Inteligência Organizacional; Mapeamento do Conhecimento; Gestão por Competências; Banco de Competências Organizacionais; Banco de Competências Individuais; e Gestão do Capital Intelectual.

Para a apresentação dos dados relativos ao estágio de implantação das práticas de GC, a seguinte escala foi utilizada: [0] não existem planos para implementação da prática; [1] existem ações planejadas para a implementação da prática no futuro; [2] a prática está em processo de implementação; [3] a prática já está implantada; [4] a prática já está implantada e apresenta resultados importantes e relevantes para a organização.

No que se refere à análise dos resultados referentes ao nível efetivo de implantação das práticas e ferramentas selecionadas, foram analisadas apenas as respostas relacionadas aos níveis 3 (a prática já está implantada) e 4 (a prática já está implantada e apresenta resultados importantes e relevantes para a organização) da escala, tendo em vista que apenas nesses dois níveis as práticas e ferramentas já estão efetivamente implantadas nas instituições analisadas.

A Tabela 1 apresenta a escala para análise dos resultados relativos ao nível efetivo de implantação das práticas de GC de recursos humanos. Faz-se importante destacar que os parâmetros foram criados de modo arbitrário, no entanto, verificou-se como sendo mais conveniente diante da estrutura da IESX analisada.

Tabela 1 - Escala para análise dos resultados relativos ao nível efetivo de implantação das práticas de GC

\begin{tabular}{cc}
\hline Nível efetivo de implantação & Estágios $\mathbf{3 + 4}$ \\
\hline Nível baixo & Entre 0 a $39 \%$ \\
Nível médio & Entre $40 \%$ a $60 \%$ \\
Nível alto & Acima de $60 \%$ \\
\hline
\end{tabular}

Fonte: Os autores (2018).

Para a análise dos resultados coletados pelo questionário, uma abordagem quantitativa foi aplicada. Os resultados foram apurados por meio de técnicas de estatística descritiva, tais como análise de distribuição de frequência absoluta e relativa dos dados. A organização dos dados e o cálculo das estatísticas foram efetuados por meio do Programa Microsoft Excel, versão 2010.

\section{RESULTADOSE DISCUSSÃO}

Apesar das práticas de GC de processos organizacionais serem de grande importância para as organizações para a execução dos procedimentos, normas e regras, otimizando a transformação em resultados positivos para a organização (BATISTA, 2006), observa-se que o nível efetivo de implantação das práticas de GC de processos organizacionais na IES X é baixo, conforme Gráfico 1 e a Tabela 2. Entre todas as práticas pesquisadas, apenas a prática Mapeamento do Conhecimento apresentou um nível efetivo de implantação médio. As demais práticas apresentaram um nível efetivo de implantação baixo. 0 Gráfico 1 apresenta o nível efetivo de implantação das práticas de GC de processos organizacionais para a IES X. 
Gráfico 1 - Nível efetivo de implementação das práticas de GC de processos organizacionais

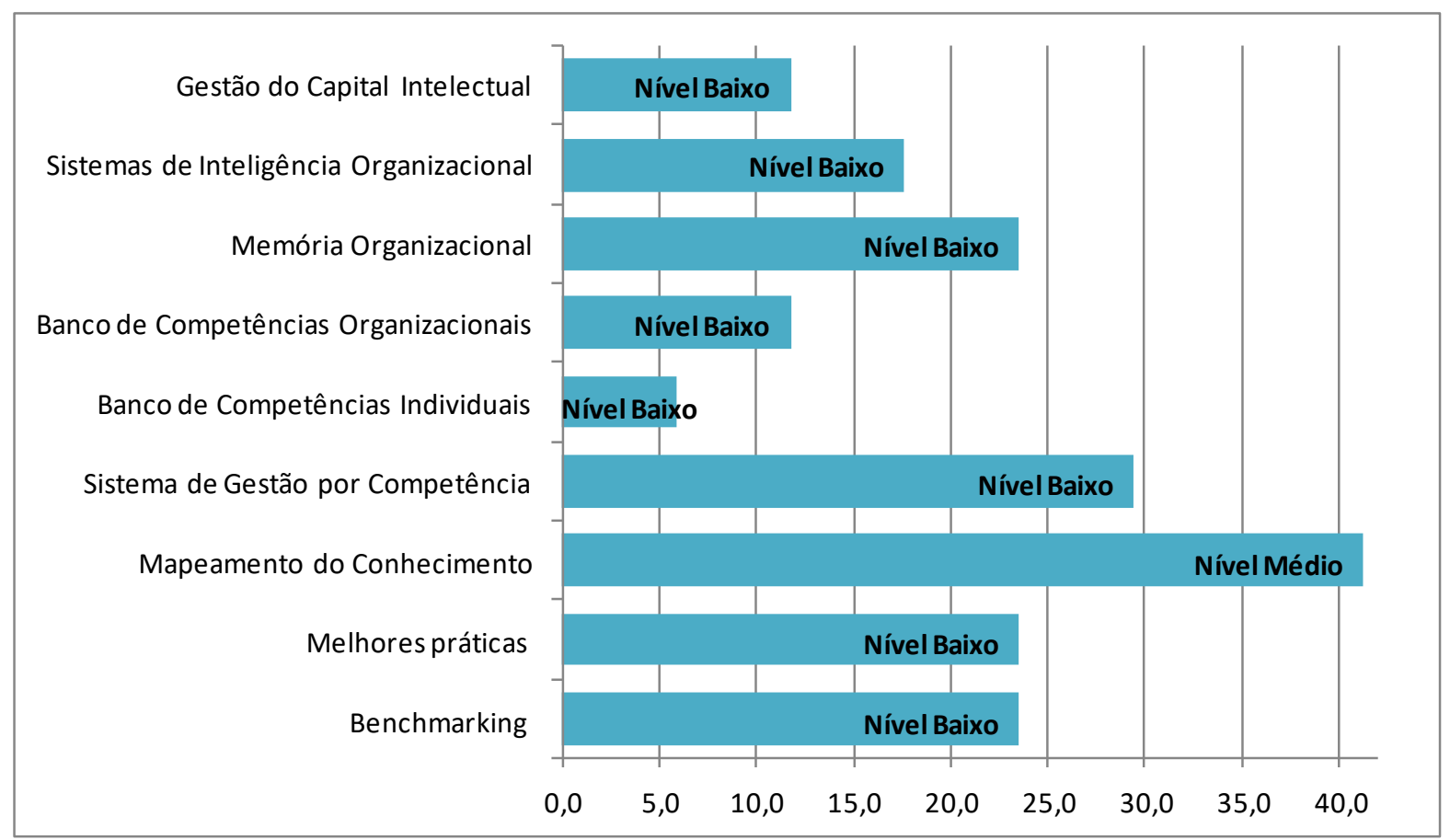

Fonte: Os autores (2018).

Conforme a Tabela 2, a pesquisa evidenciou que para $29,4 \%$ dos respondentes a IES $X$ não possui planos de implantação da prática Benchmarking, enquanto $23,5 \%$ dos respondentes consideram-na em estágio de implantação e 17,6\% identificaram a prática como estando implantada e/ou planejadas para 0 futuro. Para 5,9\%, a prática apresenta-se implantada e surtindo resultados positivos e relevantes para a organização. Percebe-se ainda que a prática - que serve para identificar, compreender, documentar e disseminar os fatores que levaram ao sucesso empresas reconhecidas como líderes de suas atividades (TEIXEIRA FILHO, 2000; SEIBEL, 2004) - é utilizada pelos coordenadores de curso. No entanto, Seibel (2004) deixa claro que a prática de Benchmarking, para ser bem-sucedida, passa pelo planejamento à definição das áreas que necessitam ser aprimoradas, assim como definição de empresas parceiras. Desta forma, observa-se a necessidade da criação de medidas que efetivem a implantação da prática Benchmarking na IES X.

Tabela 2 - Estágio de Implantação das práticas de GC de processos organizacionais

\begin{tabular}{l|c|c|c|c|c|c}
\hline \multirow{2}{*}{\multicolumn{1}{c|}{ AÇÃo OU PRÁTICA }} & \multicolumn{7}{c}{ ESTÁGIO DE IMPLANTACCÃO } \\
\cline { 2 - 7 } \multicolumn{1}{c|}{} & $\mathbf{0}$ & $\mathbf{1}$ & $\mathbf{2}$ & $\mathbf{3}$ & $\mathbf{4}$ & $\mathbf{N} / \mathbf{R}$ \\
\hline Benchmarking & 29,4 & 17,6 & 23,5 & 17,6 & 5,9 & 5,9 \\
Melhores práticas & 29,4 & 29,4 & 11,8 & 11,8 & 11,8 & 5,9 \\
Mapeamento do Conhecimento & 17,6 & 11,8 & 23,5 & 11,8 & 29,4 & 5,9 \\
Sistema de Gestão por Competência & 47,1 & 5,9 & 11,8 & 17,6 & 11,8 & 5,9 \\
Banco de Competências Individuais & 82,4 & 0,0 & 5,9 & 0,0 & 5,9 & 5,9 \\
Banco de Competências Organizacionais & 70,6 & 5,9 & 5,9 & 5,9 & 5,9 & 5,9 \\
Memória Organizacional & 47,1 & 11,8 & 11,8 & 17,6 & 5,9 & 5,9 \\
Sistemas de Inteligência Organizacional & 47,1 & 5,9 & 23,5 & 11,8 & 5,9 & 5,9 \\
Gestão do Capital Intelectual & 52,9 & 17,6 & 11,8 & 5,9 & 5,9 & 5,9 \\
\hline \multicolumn{1}{c}{ MÉDIA } & $\mathbf{4 2 , 3 1}$ & $\mathbf{1 0 , 6 8}$ & $\mathbf{1 3 , 1 6}$ & $\mathbf{1 0 , 3}$ & $\mathbf{9 , 2 4}$ & $\mathbf{5 , 9}$ \\
\hline
\end{tabular}

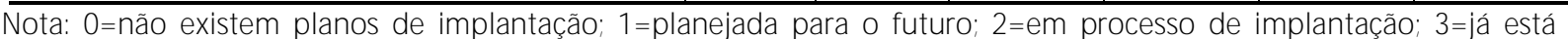

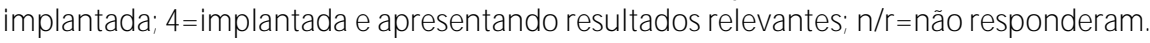


Ainda de acordo com a Tabela 2, verifica-se também que para Melhores Práticas (Best Practices), tanto o estágio caracterizado pelo planejamento para o futuro (estágio 1), quanto ao estágio de implantação não existem planos de implantação (estágio 0), receberam 29,4\% das respostas. Os estágios 2 (a prática está em processo de implantação), 3 (a prática já está implantada) e 4 (a prática está implantada e apresentando resultados relevantes) apresentaram cada $11,8 \%$ das respostas. Em consonância com Batista (2006), que define a prática como um procedimento validado para a realização de uma tarefa ou para solução de um problema, a IES X utiliza a plataforma on-line, por meio de um sistema próprio e customizado, para transmitir e documentar as Melhores Práticas, visando reduzir os problemas detectados. Para tal, a IES X segue o modelo da videoconferência, com utilização de chat ao vivo para a apresentação das Melhores Práticas e possível debate para agregar valor ao processo. Portanto, o resultado obtido pode significar que nem todos os coordenadores de cursos de graduação a distância se utilizam dessa prática mesmo estando disponível na IES $\mathrm{X}$.

A prática de Mapeamento ou Auditoria do Conhecimento foi identificada por 29,4\% dos respondentes como já implantada e surtindo resultados positivos e relevantes e por 11,8\% como já implantada. No entanto, para $23,5 \%$ dos respondentes, a prática está em processo de implantação e $11,8 \%$ vislumbram apenas que a IES X possui planos de implantação futura para a prática. Para $17,6 \%$, não há planos de implantação da prática na organização, conforme a Tabela 2 . Diante do fato da IES X ser uma organização que lida diretamente com o conhecimento e está inserida em um ambiente de competição acirrada, e dado que esta prática permite às organizações identificar e categorizar os ativos de conhecimento dentro de sua organização (YOUNG, 2010), esperava-se que a prática Mapeamento ou Auditoria do Conhecimento apresentasse um nível efetivo de implantação alto na IES X. A Tabela 2 mostra que para $47,0 \%$ dos respondentes não existem planos para implantação da prática Sistema de Gestão por Competência na organização pesquisada. Em contrapartida, a prática foi identificada por $11,8 \%$ dos respondentes como em processo de implantação ou já implantada e apresentando resultados relevantes e positivos. Para $17,6 \%$ dos participantes da pesquisa, a prática está implantada e apenas 5,9\% identificaram planos de implantação futura da prática. Diante deste resultado, verifica-se que essa prática se apresenta de maneira isolada entre os coordenadores de curso e para grande parcela dos respondentes ainda não há planos de implantação da ferramenta. Com a implantação efetiva dessa prática, tendo-se em vista as iniciativas dos respondentes, há possibilidade de mapear os conhecimentos e as habilidades necessárias para superar possíveis deficiências do setor, a fim de garantir melhoria nos processos pedagógicos e operacionais. Ou seja, a prática pode auxiliar no sentido de fomentar o desenvolvimento e a avaliação individual ou coletiva no setor.

Conforme se verifica na Tabela 2, a pesquisa evidenciou que para $82,3 \%$ dos respondentes não existem planos de implantação da prática Banco de Competências Individuais, assim como não há identificação da prática como estando implantada ou planejada para o futuro. Para 5,9\% dos coordenadores, a prática está tanto em processo de implantação quanto implantada e apresentando resultados positivos e relevantes. Diante do resultado obtido, observa-se que a prática possui um nível efetivo de implantação baixo na IES X. Isso significa dizer que a IES X não possui um banco de dados relativos aos talentos dos colaboradores da organização, de tal forma que possa subsidiar remanejamentos ou formação de equipes especializadas e de colaboradores da própria IES para solução de possíveis problemas na organização. Por se tratar de uma instituição de ensino superior, repleta de profissionais capacitados, possuindo no quadro de colaboradores coordenadores, professores e tutores que são mestres e doutores em determinadas áreas, a organização perde por não planejar e executar de maneira eficiente o mapeamento destes talentos. Conforme Batista (2006), sugere-se que a IES $X$ elabore uma lista on-line que contenha um perfil com a experiência e com as especialidades de cada usuário.

A Tabela 2 também apresenta a prática Banco de Competências Organizacionais. Para esta prática, observa-se que, para 70,5\% dos coordenadores de curso, não existem planos de implantação (estágio 0). No entanto, para 5,9\% dos respondentes, há planos de implantação da prática (estágio 1). Este mesmo patamar de coordenadores de curso respondeu que a prática se encontra em processo de implantação (estágio 2), já está implantada (estágio 3) e está implantada e apresentando resultados positivos (estágio 4). Tão relevante quanto a prática de Competências Individuais, o Banco de Competências Organizacionais representa um 
repositório de informações pertinentes ao conhecimento que cada colaborador possui sobre os processos da organização (BATISTA, 2006). A pesquisa mostrou um percentual relevante de respondentes que possuem a percepção de que sequer existem planos de implantação dessa prática na IES X, podendo-se inferir que a organização necessita investir nesse processo para otimizar os processos e garantir as conexões das competências e habilidades dos colaboradores.

De acordo com a Tabela 2, a prática Memória Organizacional foi apontada por 47,0\% dos respondentes como sem planejamento de implantação, por $11,8 \%$ tanto como estando planejada para 0 futuro, quanto estando em processo de implantação. Já para 17,6\% dos respondentes a prática está implantada e 5,9\% dos coordenadores afirmaram que a prática está implantada e apresentando resultados positivos. Dessa forma, a pesquisa evidenciou iniciativas isoladas da utilização da prática entre os respondentes e a falta de interesse em planejar sua implantação. Em consonância com Conklin (2001), Abecker et al. (1998) e Batista (2006), a implantação efetiva da prática Memória Organizacional pela IES X auxiliaria nos processos de explicitação dos conhecimentos tácitos, experiências já vividas pelos colaboradores em determinadas situações e, assim, a IES X poderá melhor gerenciar de maneira mais efetiva o conhecimento organizacional. Com isto, observa-se a necessidade de criação de medidas para ampliar a implantação efetiva desta prática na IESX.

Em relação à prática Sistemas de Inteligência Organizacional/Empresarial/ Inteligência Competitiva, verifica-se que: para 47,0\% dos coordenadores de curso, a IES X não apresenta planos de implantação desta prática; mas para $23,5 \%$ dos coordenadores, a prática apresenta-se em processo de implantação. 11,8\% identificaram a prática como estando implantada; 5,9\% indicaram que a prática está sendo planejada para implantação futura; e 5,9\% dos pesquisados, a prática já está implantada e apresentando resultados positivos e relevantes. Através da análise dos resultados obtidos, verifica-se que a prática Sistema de Inteligência Organizacional apresenta um nível efetivo de implantação baixo na IES $X$, tendo-se em vista seus benefícios. Para a organização, a implantação e utilização da prática objetiva condensar o conhecimento pulverizado e transformá-lo em inteligência organizacional para auxiliar na tomada de decisão (BATISTA, 2006). Como evidencia Batista (2006), a prática auxilia a formalização e armazenamento do conhecimento, tornando-o de fácil acesso.

Do total de entrevistados, de acordo com a Tabela 2, 52,9\% não identificaram planos de implantação para a prática Gestão de Capital Intelectual, enquanto 17,6\% indicaram ações de planejamento para o futuro. Para $11,8 \%$ dos respondentes, a prática está em processo de implantação e 11,8\% entendem a prática como estando implantada e surtindo resultados positivos e relevantes. A prática Gestão de Capital Intelectual aparece com um nível baixo de adesão entre os coordenadores de curso, uma vez que nenhum utiliza a prática efetivamente. Ainda que identificados planos futuros de implantação e iniciativas isoladas de utilização da prática, a mesma não contribui de forma efetiva para o planejamento e organização do setor pesquisado. No entanto, infere-se que a prática, conforme explana Stewart (1998), por unir os ativos intangíveis compostos por talentos, ideias, insights dos colaboradores e a relação com clientes e fornecedores, em comunhão com um sistema gerencial consoante com os objetivos da organização, possibilitando a geração de conhecimentos e promovendo inovação nos processos. Porém, para alcançar tais resultados, a iniciativa deve ser institucionalizada em todos os setores da organização.

Apesar das práticas de GC de processos organizacionais serem de grande importância para as organizações por auxiliarem na execução dos procedimentos, normas e regras, otimizando a transformação em resultados positivos para a organização (BATISTA, 2006), através da análise dos dados obtidos pela pesquisa, observa-se que o nível efetivo de implantação das práticas de GC de processos organizacionais na IES X é baixo.

Machado, Urpia e Dal Forno (2017, p. 148) afirmam que "as atividades e práticas relacionadas à gestão do conhecimento passaram a auxiliar os gestores no alcance de melhores níveis de eficiência organizacional, por meio do gerenciamento dos conhecimentos presentes em seus recursos humanos". O baixo nível das práticas de GC relacionadas à estruturação de processos organizacionais na IES seja em Benchmarking, Melhores Práticas, Memória Organizacional, Inteligência Organizacional, Gestão por Competências, Banco de Competências Organizacionais, Banco de Competências Individuais e Gestão do Capital Intelectual, indica o 
potencial a ser explorado em prol da própria organização, uma vez que a GC no contexto escolar e qualidade do ensino estão intrinsecamente imbricados, evidenciando o potencial das ferramentas para auxiliar os gestores para as tomadas de decisão quando colocadas em prática.

\section{CONSIDERAÇÕES FINAIS}

A pesquisa teve como objetivo analisar as práticas de GC relacionadas à estruturação de processos organizacionais em uma IES privada que atua na modalidade de ensino à distância no norte do Paraná.

Entre todas as práticas pesquisadas, apenas a prática Mapeamento do Conhecimento apresentou um nível efetivo de implantação médio.

Diante de uma concorrência cada vez mais acirrada entre as IES privadas que atuam na modalidade a distância e dado que a busca pela competência nesse processo leva estas organizações a tratarem o conhecimento com uma visão muito mais de gestão, pois, conforme Bolson (2012), o diferencial de uma organização não está na quantidade de conhecimento que ela produz, mas sim na eficácia em que o processo de GC ocorre na IES. Verifica-se a necessidade da IES analisada criar medidas para ampliar o nível efetivo de implantação das práticas de GC de processos organizacionais.

É importante ressaltar que em se tratando de instituição de ensino, a GC transcende os limites organizacionais. Portanto, pode-se inferir que a identificação das práticas em processos organizacionais que funcionam como facilitadores da geração, retenção, organização e disseminação do conhecimento organizacional exercem importante impacto sobre a qualidade do ensino. Por outro lado, dado o contexto de atuação de EAD da IES, o fato repercute sobre a competitividade perante o cenário de acirramento das condições de concorrência estabelecido no contexto local, regional e nacional.

Como desdobramentos futuros, sugere-se que a mesma pesquisa seja aplicada em outras IES privadas que atuam na modalidade a distância na mesma região da IES pesquisada para que seja realizada uma análise comparativa entre os dados coletados das IES. Também se verifica a necessidade de pesquisar sobre estratégias que permitam a consolidação de processos de GC em IES privadas.

\section{REFERÊNCIAS}

ABECKER, A.; BERNARD, A.; HINKELMANN, K.; KUHN, O.; SINTEK, M. Toward a technology for organizational memories. IEEE Intelligent Systems, v. 13, maio/jun. 1998.

ALBUQUERQUE JUNIOR, E.P; LAZARO, J.C; LIMA, B.C.C. Inovação, Estratégia e Competitividade nas Empresas Brasileiras: Uma Investigação Inicial Sobre Atividades Inovativas e Impactos, Conforme o Pintec 2008. RaUnp, Ano III, n. 2 - abr./set. 2011. Disponível em: https.//repositorio.unp.br/index.php/raunp/article/view/85/92. Acesso em: 31 mar. 2018.

ANDRADE, E. P.; SANTIAGO, A. C. Mapeamento de conhecimento: localizando as fontes de riqueza de uma organização. In: ENCONTRO NACIONAL DE ENGENHARIA DE PRODUÇÃO (ENEGEP), 21., Salvador, Bahia, 2001. Anais [...]. Salvador: ANPAD, 2001.

APQC. AMERICAN PRODUCTIVITY AND QUALITY CENTRE. Knowledge Management Glossary. Houston: APQC, 2014.

ARAÚJ O, J . A.; MARTINS, I. Gestão Por Competências na Administração Pública: Uma Análise Bibliométrica a Partir do Decreto Lei 5.707/2006. Revista Gestão.Org., v. 12, n. 2, p. 153-162, 2014. Disponível em: http://www.spell.org.br/documentos/ver/39905/gestao-por-competencias-na-administracao-publica--umaanalise-bibliometrica-a-partir-do-decreto-lei-5-707-2006. Acesso em: 5 dez. 2017.

ARGYRIS, Chris; SCHÖN, Donald A. Organizational Learning II. Theory, Method and Practice. Reading: Addison Wesley, 1996. 
BATISTA, F. F. Modelo de gestão do conhecimento para a administração pública brasileira: como implementar a gestão do conhecimento para produzir resultados em benefício do cidadão. Brasília: Ipea, 2012.

0 desafio da gestão do conhecimento nas áreas de administração e planejamento das instituições federais de ensino superior (IFES). Texto para Discussão, n 1181. IPEA, Brasília, maio de 2006.

; XAVIER, A.C.R.; MENDES, L.C.; ROSENBERG, G. Gestão do Conhecimento em organizações públicas de saúde. Texto para Discussão, n 1316. IPEA, Brasília, dezembro de 2007.

; RECH, A.R.; GOMES, C.A.; SANTOS, D.L.N.; ANDRADE, E.C.S; MALLMANN, M.L; FERREIRA, R.M. P. M.; COSTA, V.S. Casos Reais de implantação do modelo de gestão do conhecimento para a administração pública brasileira. Texto para Discussão, n 1941. IPEA, Brasília, março de 2014.

; QUANDT, C.O. PACHECO, F.F.; TERRA, J.C.C. Gestão do conhecimento na administração pública. Texto para Discussão, n ${ }^{\circ}$ 1095. IPEA, Brasília, junho de 2005.

BENTO, J. C. et al. Práticas da gestão do conhecimento em recursos humanos em instituição de ensino superior à distância. Espacios, v. 37, n. 29, p. 21-30, 2016.

BELL, D. The coming of the post industrial society: a venture in social forecasting. New York: Basic Books, 1974.

BOLSON S. B. Gestão do Conhecimento: estudo em uma IES Tecnológica. Dissertação (Administração) Universidade Potiguar, Natal, 2012.

BURNETT, S.; ILLINGWORTH, L.; WEBSTER, L. Knowledge Auditing and Mapping: A Pragmatic Approach, Knowledge and Process Management, v. 11, n. 1, p. 25-37, 2004.

CASSIOLATO, J . E. A Economia do conhecimento e as novas políticas industriais e tecnológicas. In: LASTRES, Helena M. M.; ALBAGLI, Sarita (org.). Informação e globalização na era do conhecimento. Rio de J aneiro: Campus, 1999. p. 164-190.

CONKLIN, J. Designing Organizational Memory: Preserving Intellectual Assets in a Knowledge Economy. Designing Organizational Memory, p. 1-41, 2001.

DAVENPORT, T.H.; PRUSAK, L. Conhecimento Empresarial: como as organizações gerenciam o seu capital intelectual. Rio de J aneiro: Campus, 1998.

DUTRA, J.S. (org.). Gestão por competências: um modelo avançado para o gerenciamento de pessoas. São Paulo: Gente, 2001.

EKIONEA, B.; BERNARD, P.; PLAISENT, M. Towards a maturity model of knowledge management competences as an organizational capability. In: INTERNATIONAL CONFERENCE ON E-BUSINESS AND E-GOVERNMENT (ICEE), 2011, Shanghai. Proceedings [...]. Shanghai: IEEE, 2011.

FREIRE, P. S.; SPANHOL, F. J. Conhecimento organizacional: produto ou processo? Perspectivas em Gestão \& Conhecimento, v. 4, n. 5, p. 3-21, 2014.

GATTONI, R. L. C. Gestão do conhecimento organizacional na condução de projetos corporativos em tecnologia da informação - um caso prático. Dissertação (Mestrado em Ciência da Informação) Universidade Federal de Minas Gerais, Belo Horizonte, 2000.

GONZALEZ, R. V. D.; MARTINS, M. F. O processo de gestão do conhecimento: uma pesquisa teórico conceitual. Gestão e Produção, v. 24, n. 2, p. 248-265, 2017. Disponível em: http://dx.doi.org/10.1590/0104-530X089315. Acesso em: 15 jan. 2017. 
HYLTON, A. A KM Initiative is Unlikely to Succeed Without a Knowledge Audit. Beverly: Hylton Associates, 2002.

MACHADO, C. P.; URPIA, A. G. B. da C.; DAL FORNO, L. F. Gestão do conhecimento no ensino público: uma agenda de pesquisa. Revista Cesumar Ciências Humanas e Sociais Aplicadas, v. 22, n.1 , p. 145-165, jun./jun. 2017.

NONAKA, I. The Knowledge-Creating Company. Harvard Business Review, v. 69, p. 96-104, 1991.

NONAKA, I.; TAKEUCHI, H. Criação de conhecimento na empresa: como as empresas japonesas geram a dinâmica da informação. Rio de Janeiro: Campus, 1997.

NONAKA, I.; TAKEUCHI, H. Teoria da criação do conhecimento organizacional. In: TAKEUCHI, H.; NONAKA, I. Gestão do conhecimento. Porto Alegre: Bookman, 2008. p. 54-90.

PEREIRA, M. O. F. P.; SILVA, H. de F. N.; PINTO, J. S. de P. A memória organizacional nos processos de gestão do conhecimento: um estudo na Universidade Federal do Paraná. Informação \& Informação, Londrina, v. 21, n. 1, p. $348-374,2016$.

POLANYI, M. The tacit dimension. Garden City, New York: Doubleday \& Company, Inc. 1966.

PONCHIROLLI, O. Capital humano: sua importância na gestão estratégica do conhecimento. Curitiba: Juruá, 2009.

PURCIDONIO, P.M. Práticas de Gestão do Conhecimento em Arranjo Produtivo Local: o setor moveleiro de Arapongas - PR. 2008. Dissertação (Mestrado) - Universidade Tecnológica Federal do Paraná, Ponta Grossa, 2008.

SEIBEL, S. Um modelo de benchmarking baseado no sistema produtivo classe mundial para avaliação de práticas e performances da indústria exportadora brasileira. Tese (Doutorado em Engenharia de Produção e Sistemas) - Universidade Federal de Santa Catarina, Florianópolis, 2004.

SILVA, O.F.P. Avaliando os Sistemas de Informações Executivas nos Processos Decisórios das Instituições Universitárias Brasileiras. Dissertação (Mestrado) - Universidade Federal de Santa Catarina, Florianópolis, 2000.

SCHREIBER, D. A influência da cultura organizacional sobre a gestão do conhecimento em P\&D. Gestão \& Planejamento, Salvador, v. 16, n. 2, p. 240-261, 2015.

STEWART, T. A. Capital intelectual: a nova vantagem competitiva. Rio de Janeiro: Elsevier, 1998.

SVEIBY, K. E.; MARTINS, J. R. Gestão do conhecimento: as lições dos pioneiros. 2005. Disponível em: http://www.globalbrands.com.br/artigos-pdf/knowledge-management.pdf. Acesso em: 31 mar. 2018.

TEIXEIRA FILHO, J. Gerenciando Conhecimento: como a empresa pode usar a memória organizacional e a inteligência competitiva no desenvolvimento de negócios. Rio de Janeiro: Ed. SENAC, 2000.

TERRA, J.C.C. Gestão do conhecimento: o grande desafio empresarial: uma abordagem baseada no aprendizado e na criatividade. São Paulo: Negócio Editora, 2001.

YOUNG R. Knowledge Management Tools and Techniques Manual. Tóquio: Asian Productivity Organization (APO), 2010.

ZANGISKI, M. A.S.G.; LIMA, E. P.; COSTA, S. E. G. Aprendizagem organizacional e desenvolvimento de competências: uma síntese a partir da gestão do conhecimento. Revista Produto \& Produção, v. 10, n. 1, p. 54-74, fev. 2009. Disponível em: http://www.seer.ufrgs.br/ProdutoProducao/article/view/7787. Acesso em: 31 mar. 2018. 